\title{
Morphometric comparisons of plant-mimetic juvenile fish associated with plant debris observed in the coastal subtropical waters around Kuchierabu-jima Island, southern Japan
}

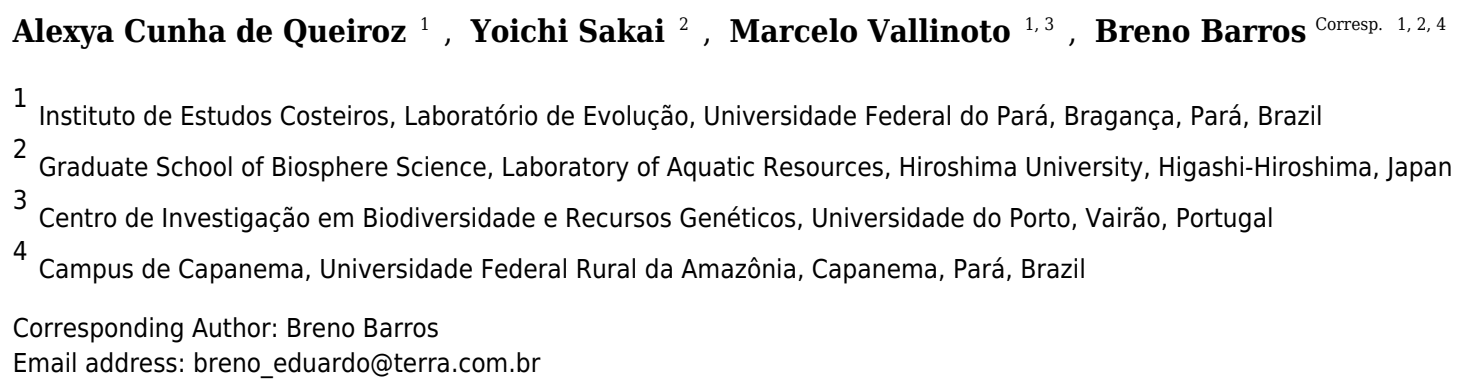

The general morphological shape of plant-resembling fish and plant parts were compared using a geometric morphometrics approach. Three plant-mimetic fish species, Lobotes surinamensis (Lobotidae), Platax orbicularis (Ephippidae) and Canthidermis maculata (Balistidae), were compared during their early developmental stages with accompanying plant debris (i.e. leaves of several taxa) in the coastal subtropical waters around Kuchierabu-jima Island, closely facing the Kuroshio Current. The degree of similarity shared between the plant parts and co-occurring fish species was quantified, however fish remained morphologically distinct from their plant models. Such similarities were corroborated by analysis of covariance and linear discriminant analysis, in which relative body areas of fish were strongly related to plant models. Our results strengthen the paradigm that morphological clues can lead to ecological evidence to allow predictions of behavioural and habitat choice by mimetic fish, according to the degree of similarity shared with their respective models. The resemblance to plant parts detected in the three fish species may provide fitness advantages via convergent evolutionary effects. 
1 Morphometric comparisons of plant-mimetic juvenile fish associated with plant debris observed

2 in the coastal subtropical waters around Kuchierabu-jima Island, southern Japan

3

4 Alexya C. Queiroz ${ }^{1}$, Yoichi Sakai ${ }^{2}$, Marcelo Vallinoto ${ }^{1,3}$, and Breno Barros ${ }^{1,2,4}$

5

$6 \quad{ }^{1}$ Universidade Federal do Pará - campus de Bragança, Laboratório de Evolução, Instituto de

7 Estudos Costeiros, Alameda Leandro Ribeiro, s/n, Aldeia, CEP 68600-000 Bragança, Pará,

8 Brazil

$9{ }^{2}$ Graduate School of Biosphere Science, Hiroshima University, 1-4-4, Kagamiyama, 739-8528.

10 Higashi-Hiroshima, Japan

$11{ }^{3}$ CIBIO-InBIO, Centro de Investigação em Biodiversidade e Recursos Genéticos, Campus

12 Agrário de Vairão, Universidade do Porto, 4485-661. Vairão, Portugal

$13{ }^{4}$ Universidade Rural da Amazônia - campus de Capanema, Rua João Pessoa, 121, CEP 68700-

14 030, Capanema, Pará, Brazil.

15

16 Running title: Comparative fish and plant morphometrics

17

18 Corresponding author: breno_eduardo@terra.com.br

19 Tel: +55 9130756125 
22 Abstract

23 The general morphological shape of plant-resembling fish and plant parts were compared using a

24 geometric morphometrics approach. Three plant-mimetic fish species, Lobotes surinamensis

25 (Lobotidae), Platax orbicularis (Ephippidae) and Canthidermis maculata (Balistidae), were

26 compared during their early developmental stages with accompanying plant debris (i.e. leaves of

27 several taxa) in the coastal subtropical waters around Kuchierabu-jima Island, closely facing the

28 Kuroshio Current. The degree of similarity shared between the plant parts and co-occurring fish

29 species was quantified, where fish and plants presented highly similar morphometric associations,

30 yet remaining morphologically distinct. Such similarities were corroborated by analysis of

31 covariance and linear discriminant analysis, in which relative body areas of fish were strongly

32 related to plant models. Our results strengthen the paradigm that morphological clues can lead to

33 ecological evidence to allow predictions of behavioural and habitat choice by mimetic fish,

34 according to the degree of similarity shared with their respective models. The resemblance to

35 plant parts detected in the three fish species may provide fitness advantages via convergent

36 evolutionary effects.

37

38 Key-words: Protective camouflage, Masquerade, Coastal Environments, Shape analysis,

39 Convergent evolution 
42

43

44

45

46

47

48

49

50

51

52

53

54

55

56

57

58

59

60

61

62

63

64

\section{Introduction}

Mimesis is defined as a phenotype evolved in response to selective pressures favouring individuals that can disguise their identity by masquerading as another organism (Pasteur, 1982; Skelhorn, Rowland \& Ruxton, 2010a; Skelhorn et al., 2010b). Mimesis in fish is a relatively well-studied subject (Wickler, 1968; Moland, Eagle \& Jones, 2005; Robertson, 2013), particularly regarding deceptive resemblance to plant parts via protective camouflage, which is a known feature in several freshwater and marine fish species, as extreme crypsis examples of protective resemblance (Breder, 1946; Randall, 1965, 2005a; Vane-Wright, 1980; Sazima et al., 2006). Although these reports have addressed the patterns and general similarities in morphology or colouration of model plant parts and mimetic fish, few studies have examined similarities among them based on morphological and/or ethological details (Barros et al. 2008, 2011, 2012).

Studies focusing on morphology and geometric morphometrics frequently used fish species as models, and several authors have suggested that morphological clues can be used as ecological predictors from basic behavioural constraints, such as swimming mode (Walker, 2004; Comabella, Hurtado \& García-Galano, 2010; Xiong \& Lauder, 2014), feeding behaviour (Galis, 1990; Franssen, Goodchild \& Shepard, 2015) and habitat choice (Loy et al., 1998; Gibran, 2010; Soares, Ruffeil \& Montag, 2013), especially in juvenile fish, suggesting that such changes are important for improving fitness and increasing the chance for survival during subsequent ontogenetic stages (Barros et al., 2011; Comabella et al., 2013). Nevertheless, such a tool has not been used to establish comparisons among distant taxa belonging to completely different groups (i.e. fish and plants). In the present study, previously well-known plant-mimetic juvenile fish, the tripletail, Lobotes surinamensis (Bloch, 1790), the orbicular batfish, Platax 
65 orbicularis (Forsskål, 1775) and the ocean triggerfish, Canthidermis maculata (Bloch, 1786)

66 were compared with their respective plant models co-occurring in the field to objectively

67 evaluate their resemblance in shape to their respective models. All fish and plant models were

68 observed and sampled from Kuchierabu-jima Island and its surrounding waters, which are 69 subjected to a strong influence of Kuroshio Current.

70 Lobotes surinamensis is generally found in shallow brackish water habitats but may occur

71 far offshore with drifting algae or flotsam, and juveniles may lie on their side matching the

72 colour of the plant debris, from near black to yellow (Randall, 2005b). Juveniles are usually

73 dark-coloured, presenting drifting swimming patterns among dry leaves, exhibiting similar

74 movements to their associated plant model (Uchida, 1951; Randall, 2005b). Uchida (1951) also

75 described that young C. maculata resemble pieces of pine bark and were observed drifting

76 among pieces of bark in a horizontal swimming posture, suggesting mimetic effects. Juveniles of

77 P. orbicularis look similar to yellow waterlogged jack tree leaves (genus Rhizophora) and

78 greatly resemble floating dead leaves (Wiley, 1904; Breder, 1946). Randall (1960) reported that

79 larger individuals (87 mm standard length [SL]) resemble large sea hibiscus leaves (Hibiscus

80 tiliaceus) with a yellowish-brown colouration, with dorsal and anal fins appearing to lengthen

81 with growth. Such drastic changes in morphological shape occur in juvenile P. orbicularis while

82 they maintain a resemblance to drifting leaves (Barros et al., 2015).

83 The novel comparative methods presented herein may provide useful associations between

84 behavioural ecology and morphological studies. We tested the null hypothesis of a lack of shape

85 similarity among the studied fish and plant parts, considering both classic and geometric

86 morphometrics comparative approaches. We briefly discuss the functional contributions of

87 camouflage characteristics to fish fitness using mimetic shape attributes as a disguise based on 
88

89

90

91

92

93

94

95

96

97

98

99

100

101

102

103

104

105

106

107

108

109

110

morphological resemblance data among fish and model plants, adopting the concepts of cryptic mimesis as synonym of protective camouflage or masquerading, following the definitions as proposed by Pasteur (1982), where all fish samples are defined as "mimetic fish" and all plant part samples as "models", instead of adopting the terminology as proposed by Skelhorn, Rowland \& Ruxton (2010a). This is due to the highly dynamic environments such fish usually occur, where mimetic behaviour is achieved not only by appearance, but also through actively behaving alike the drifting models (Barros et al., 2008).

\section{Material and Methods}

7

\subsection{Sampling}

Sampling was mainly conducted in the port of Honmura, Kuchierabu-jima Island (Ohsumi Group, $30^{\circ} 28^{\prime} \mathrm{N}, 130^{\circ} 10^{\prime} \mathrm{E}$ ), southern Japan, during diurnal observations July 3-14, 2011 (S1

Fig.). The island closely faces the Kuroshio Current and maintains a rich subtropical fish fauna (Gushima \& Murakami, 1976). Fish samples and plant debris were collected using hand nets, and the sampled fish were euthanized using $5 \mathrm{ml} 95 \%$ eugenol in $1 \mathrm{~L}$ ethanol as a stock solution All fish samples were preserved in order to maintain integrity of peripheral structures and general shape, and were photographed as soon as possible, in order to avoid any arching or deformation effect from the fixation protocols established (Valentin et al., 2008). All plant materials were sampled at the island along with their associated fish. Of this, $20 \mathrm{ml}$ was added to each $1 \mathrm{~L}$ of water containing the fish to be euthanized to minimise suffering, following international ethical standards (Jenkins et al., 2014). As there is no national Japanese licensing framework, samples were collected following the "Guidelines for Proper Conduct of Animal 
111 Experiments" set out by the Hiroshima University Animal Research Committee, which are based

112 on international ethical standards, and only after obtaining local community permission.

113 Fish samples from Kuchireabu-jima Island were identified to as low a taxonomic category as

114 possible, according to available literature (Nakabo, 2002; Nelson, 2006; Okiyama, 2014). Fifteen

115 mimetic fish specimens of three species (Fig. 1A-C) were observed to drift around plant debris:

116 Lobotes surinamensis (Lobotidae; $n=6, \mathrm{TL}=3.89 \pm 0.46 \mathrm{~cm} ;$ AVE \pm SDEV values), Platax

117 orbicularis (Ephippidae; $n=7 \mathrm{TL}=2.05 \pm 0.42 \mathrm{~cm}$ ) and Canthidermis maculata (Balistidae; $n$

$118=2, \mathrm{TL}=3.15 \pm 0.98 \mathrm{~cm})$. An additional 24 fish specimens $(\mathrm{n}=14$ for $L$. surinamensis, $\mathrm{n}=10$

119 for C. maculata) sampled in subtropical waters of Kagoshima Prefecture were also obtained from

120 the collections of the Kagoshima University Museum (KAUM) to enhance and equalize sample

121 size of our data set for the statistical analyses (see below). The KAUM samples were all

122 juveniles, with relatively similar standard length as those observed (L. surinamensis TL $=4.92 \pm$

$1232.02 \mathrm{~cm}$, and C. maculata $\mathrm{TL}=3.95 \pm 0.98 \mathrm{~cm}$ ) and collected near to the present study area, i.e.,

124 Satsuma Peninsula of mainland Kagoshima, Tanega-shima Island, and Yaku-shima Island

$125\left(31^{\circ} 28^{\prime}-31^{\circ} 33^{\prime} \mathrm{N}, 130^{\circ} 11^{\prime}-130^{\circ} 51^{\prime} \mathrm{E}\right)$ (for details refer to S2 Dataset). Of these, the most images

126 were provided by the KAUM ( $\mathrm{N}=5$ for $C$. maculata and $\mathrm{N}=11$ for $L$. surinamensis $)$, taken

127 from fresh specimens. All other samples were photographed in the Laboratory of Biology of

128 Aquatic Resources, at the Hiroshima University, and only those with all peripheric structures

129 intact were considered in the analysis. No arched or deformed specimens were used during the

130 analyses, in order to prevent from any misinterpretation of data, as inconclusive attempts to

131 explain such posture variations by any possible biological factors, as allometric growth or even

132 sexual dimorphism (Valentin et al., 2008). 
Also, additional twelve samples of $P$. orbicularis $(\mathrm{TL}=2.05 \pm 0.91 \mathrm{~cm})$ collected during

134 previous surveys on Kuchierabu-jima Island (Barros et al. 2008, 2011) were eventually

135 employed, in order to equalize $\mathrm{N}$ size. These were also fixed using the same protocol as

136 standardized herein, being photographed soon after sampling. A total 52 individual mimetic

137 fishes were analysed.

Floating plant debris (hereafter, models, $n=43$ ) were collected using hand nets and sorted,

139 then visually subdivided using two subjective criteria (round shapes, as for the Podocarpaceae

140 Nageia nagi and the Sapindaceae Acer morifolium; or elongated shapes, as for the Laureaceae

141 Neolitsea sericea and for the Fagaceae Castanopsis sieboldii; Fig. 1D-E), regardless of

142 taxonomy and dried in paper envelopes until they were photographed for further analyses.

143 High resolution digital pictures of the left lateral view of the mimetic fish and model

144 samples were taken over a black background using a Nikon D700 equipped with AF-S 60-mm

145 immersive lens and a stand table with a reference scale of $1 \mathrm{~cm}$ for the fish and models. The left

146 lateral view of the models was defined as the "dorsal view of leaves with the petiole oriented to

147 the right". Artificial light was used to avoid shading morphological structures.

148

149 2.2. Data Analyses

150 Sixteen landmarks (LM) were established for the mimetic fish and models using ImageJ v. 1.47

151 software for geometric morphometrics purposes (Abramoff, Magelhaes \& Ram, 2004).

152 Homologous LM for the mimetic fish were marked obeying the morphological structures

153 constrained or related to mimetic behaviour to cover the fish general outline profile, including

154 peripheral structures (Fig. 1A, Table I). We established equidistant 16 semilandmarks (SLM) for

155 each model using the ImageJ grid tool to cover all lateral profiles of the model, obeying the same 
156 marking distribution as for the mimetic fishes (Fig. 1D). Raw coordinates LM and SLM data

157 were implemented in MorphoJ v. 1.02n software (Klingenberg, 2011), where preliminary

158 adjustments, such as the Procrustes fit, and creation of the data matrix, were done. The

159 morphometric comparisons among the fish and models were not intended to analyse homologous

160 patterns, as we were interested in shape similarities randomly shared among the mimetic fish and

161 their respective models distributed in the same environment, from a geometric morphometrics

162 perspective. Therefore, the necessity of marking peripheral anatomic structures in the mimetic

163 fish, instead of fins insertions only, in order to check for general appearance of mimetic fish with

164 the plant models.

165 Data analyses were performed with Geomorph v. 2.0 software (Adams \& Otarola-Castillo,

166 2013). A post-hoc general Procrustes analysis (GPA) and principal components analysis (PCA)

167 were run followed by analysis of variance (ANOVA) to compare the mimetic fish and models

168 plotted together in the analyses. Also, a linear discriminant function was run, in order to visualize

169 how close were these group associations, using the package MASS v. 7.3-42 (Venables \&

170 Ripley, 2002).

171 In addition, individual TL and relative body area (BA, $\left.\mathrm{cm}^{2} / \mathrm{TL}\right)$ of the fish and models

172 were calculated using ImageJ to establish interdependent comparisons among the fish species

173 and plant debris via analysis of covariance (ANCOVA), followed by a linear discriminant

174 analysis (LDA), to accurately predict whether the mimetic fish can be misclassified as a model.

175 BA was chosen because of its importance for discriminating teleost aggregations (Gómez-

176 Laplaza \& Gerlai, 2013). Fish were measured from the tip of the snout to the edge of the caudal

177 fin (TL), and models were measured from edge to edge and considered TL. All statistical 
178 analyses were conducted in 'R' v. 3.1.3 (R Development Core Team, 2015), and all relevant data

179 for the current analysis are available within this paper (S2 dataset).

180

181

182

183

184

185

186

187

188

189

190

191

192

193

194

195

196

197

198

199

200

\section{Results}

Mimetic fish were observed mimicking plant debris near the water surface in all extensions of the port of Honmura. The mimetic assemblages resembled the models in shape, colour and drifting movements, having shared the same environment during the entire sampling period. All fish drifted among fallen plant debris near the water surface.

The visual GPA analysis indicated a significant variance in the shape configurations among the different models (Fig. 2A) and mimetic fish (Fig. 2B). All-pooled data showed a relative tendency of the mimetic fish to resemble plant debris with $\sim 24 \%$ of the variation explained in PC1 and $\sim 10 \%$ of the variation explained in PC2 (ANOVA $F_{2,52}=40.97, P<0.001$, Fig. 2C), yet remaining morphologically distinct, as observed in the GPA analyses.

BA of the mimetic fish and models regressed against TL revealed a significant interdependency (ANCOVA, $F_{2,96}=92.06, P<0.001$; Fig. 3), where juvenile $L$. surinamensis, $P$. orbicularis and C. maculata have shown a size gradient, sharing similar BA with round and elongated leaves of different sizes, accordingly to different growth stages of each mimetic fish species, with some deviation observed for the round leaf models. These results were corroborated by LDA, which has shown high similarities in shape of mimetic fish and models, with a $52.52 \%$ probability of misclassification among the observed individuals. Details on both ANCOVA and LDA can be found in S2 dataset. 


\section{4. Discussion}

202

203 The present results show shape heterogeneity among mimetic fish and plant models, with a 204 significant level of similarity shared in their general external shape profile. Such results are 205 highly expected, as mimetic behaviour is more likely to be driven by a combination of factors 206 (i.e.: shape, colour and movements) than solely by morphological attributes (Wickler, 1968; 207 Pasteur, 1982). Although the importance of floating plant debris for passive transportation, 208 providing shelter and feeding grounds for fish in coastal environments has been evaluated 209 (Castro, Santiago \& Santana-Ortega, 2001; Vandendriessche et al., 2007), the closeness of these 210 interactions has not been investigated, particularly regarding plant resemblance by fish.

211 Arching effects due to fixation protocols are known to strongly influence geometric 212 morphometric analyses (Valentin et al., 2008). Although we have combined data from museum 213 specimens with our own samples, we have selected only intact individuals for the present 214 analyses. According to observed shape similarities shared among the mimetic fish and models, it 215 was clear that the present fish assemblage accompanied their respective models, being probably 216 dependent on drifting plant material for survival, also suggested by the linear model of 217 covariance shared amongst drifting fish and plants. While not the primary goal of the present 218 study, such association might suggest an allometric dependence for the plant mimetic species, at 219 least until a given ontogenetic stage when such fish species suffer significant changes in 220 morphology and behaviour, cessing with the mimetic association with plants (Barros et al., $2212015)$.

222 The concepts regarding mimetic behaviour are still a matter of discussion, as it is difficult 223 to define a case of mimetic association using only a shape resemblance to another 
224 animal/inanimate object (Skelhorn, Rowland \& Ruxton, 2010a; Skelhorn et al., 2010b),

225 especially in marine systems (Robertson, 2013; 2015). The observed species herein not only

226 presented good shape similarity with the models, but also behaved alike, via drifting movements

227 along with their respective models, far away from being "inanimate" (BBarros, personal

228 observation; S3 video). Close resemblance of fish to their models in shape and drifting behaviour

229 at the water surface environment could confuse visually oriented predators through the

230 camouflage effect. Thus, "mimetic behaviour" was a valid classification in the present case.

All species tested in the present study, such as L. surinamensis (Lobotidae), C. maculata

232 (Balistidae) and P. orbicularis (Ephippidae) have been described previously as resembling dried

233 leaves in shallow water (Uchida, 1951; Breder, 1942, 1946, 1949; Randall \& Randall, 1955;

234 Barros et al., 2008, 2011, 2012), and are commonly found in the surveyed area (Motomura et al., 235 2010).

Although coastal fish resembling a plant via cryptic colouration has been an intriguing

237 subject since the early reports, the present study is the first attempt to establish analytical

238 comparisons between mimetic fish and models at the morphometrics level. Kelley \& Merilaita

239 (2015) suggested that successful crypsis in fish is more likely achieved through colouration, via a

240 background matching effect. Although we did not test the predation rate of mimetic fish nor for

241 any colour influence, our results add relevant information, in which background matching is

242 achieved not only by cryptic colouration (Breder, 1946; Randall \& Randall, 1960; Randall,

243 2005b), but also through shape and behavioural resemblance of mimetic fish to their respective

244 models. The present level of protective camouflage shared by the fish assemblage analysed

245 herein might be important against potential aerial and bottom predators, as background colour

246 matches surrounding environments (Donnely \& Whoriskey Jr., 1991; Cortesi et al., 2015; Kelley 
$247 \&$ Merilaita, 2015). However, no predatory attempt by a bird species has been observed. Further

248 experiments and field observations of all observed species are necessary to test this assumption.

249 The co-occurring mimetic assemblages observed herein are a typical example of

250 convergent evolution in a coastal environment (Endler, 1981; Hamner, 1995; Johnsen, 2014).

251 Some taxa analysed undergo numerous morphological and ethological changes. For example, $P$.

252 orbicularis adults inhabit deeper environments, changing in both shape and behaviour within the

253 settlement (Kuiter \& Debelius, 2001; Barros et al., 2011). As major morphological changes are

254 usually expected through ontogeny of several fish groups (Galis, 1990; Loy et al., 1998;

255 Comabella, Hurtado \& García-Galano, 2010; Leis et al. 2013; Nikolioudakis, Koumoundouros \&

256 Somarakis, 2014; Barros et al., 2015), resemblance to leaves by the fish species observed here

257 may be crucial for first settlement, as it could improve survival chances (Johnsen, 2014).

The Kuroshio Current is regarded as a key factor for passive transportation of masses of

259 plant and algae material and juvenile fishes closely associated with, as such ichthyofauna use the 260 plant debris as both shelter and food source (Kimura et al., 1998). Strictly morphological studies

261 are ineffective for providing all of the clues necessary to interpret the natural history of most

262 living organisms (Scholtz, 2010). The present observations support fundamental information on

263 the distributions of these fish species during early stages, their life history and evolutionary paths

264 if combined with mimetic fish and model ethological and ecological data that are available for

265 some taxa (Barros et al., 2008, 2011, 2012). Although refinements to the methodologies are

266 necessary, this new comparative approach may stimulate discussion of morphology as a

267 predictor of ecology (Douglas \& Matthews, 1992; Gibran, 2010; Oliveira et al., 2010).

268

269 Acknowledgements 
270 We thank all members of the Kuchierabu-jima Island community, particularly M. Yamaguchi,

271 the crew of the Laboratório Multi-Imagem and F. R. R. de Oliveira (UFPA), and A. Akama

272 (MPEG) for criticism and logistic and technical support during this study. We are deeply grateful

273 to Dr. Hiroyuki Motomura (Kagoshima University Museum) for supplying additional samples,

274 and Dr. Yuki Kimura and Ms. Misaki Fujisawa (Hiroshima University) for technical support.

275 This study is in memory of Dr. Kenji Gushima.

276

\section{References}

278 Abramoff, M. D., Magelhaes, P. J. \& Ram S. J. (2004). Image processing with imageJ.

279 Biophotonics International 11, 36-42.

280 Adams, D. C. \& Otarola-Castillo, E. (2013). Geomorph: an R package for the collection and 281 analysis of geometric morphometric shape data. Methods in Ecology and Evolution 4, 393282399.

283 Barros, B., Sakai, Y., Hashimoto, H. \& Gushima, K. (2008). Feeding behaviors of leaf-like 284 juveniles of the round batfish Platax orbicularis (Ephippidae) on reefs of Kuchierabu-jima 285 Island, southern Japan. Journal of Ethology 26, 287-293.

286 Barros, B., Sakai, Y., Hashimoto, H. \& Gushima, K. (2011). Effects of prey density on nocturnal 287 zooplankton predation throughout the ontogeny of juvenile Platax orbicularis (Teleostei:

288 Ephippidae). Environmental Biology of Fishes 91 (2), 177-183

289 Barros, B., Sakai, Y., Hashimoto, H., Gushima, K. \& Vallinoto, M. (2012). "Better off alone than 290 in bad company": Agonistic colour display in mimetic juveniles of two ephippid species.

291 Journal of Fish Biology 81 (3), 1032-1042.

292 Barros, B., Sakai, Y., Hashimoto, H., Gushima, K., Oliveira, Y., Abrunhosa, F. A. \& Vallinoto, 

M. (2013). Are ephippid fish a "sleeping functional group"? - Herbivory habits by four

294 Ephippidae species based on stomach contents analysis. In Herbivory (Barros, B. \&

295 Fernandes, M. E. B. eds), pp 33-46. Rijeka, Croatia, InTech press.

296 Barros, B.; Sakai, Y.; Pereira, P. H. C.; Gasset, E.; Buchet, V.; Maamaatuaiahutapu, M.; Ready, 297 J. S.; Oliveira, Y.; Giarrizzo, T. \& Vallinoto, M. (2015) Comparative allometric growth of the 298 mimetic ephippid reef fishes Chaetodipterus faber and Platax orbicularis. PLoS ONE 10(12): 299 e0143838. doi:10.1371/journal.pone.0143838

300 Breder, C. M. (1946). An analysis of the deceptive resemblances of fishes to plant parts, with 301 critical remarks on protective coloration, mimicry and adaptation. Bulletin of the Bingham 302 Oceanographic Collection 10,1-49.

303 Castro, J. J., Santiago, J. A. \& Santana-Ortega, A. T. (2001). A general theory on fish 304 aggregation to floating objects: an alternative to the meeting point hypothesis. Reviews in Fish 305 Biology and Fisheries 11, 255-277.

306 Comabella, Y., Hurtado, A. \& García-Galano, T. (2010). Ontogenetic Changes in the 307 Morphology and Morphometry of Cuban Gar (Atractosteus tristoechus). Zoological Science $308 \quad 27,931-938$.

309 Comabella, Y., Azanza, J., Hurtado, A., Canabal, J. \& García-Galano, T. (2013). Allometric 310 growth in cuban gar (Atractosteus tristoechus) larvae. Universidad y Ciencia 29 (3), 301-315. 311 Cortesi, F., Feeney, W. E., Ferrari, M. C. O., Waldie, P. A., Phillips, G. A. C., McClure, E. C., 312 Sköld, H. N., Salzburger, W., Marshall, N. J., Cheney, K. L. (2015). Phenotypic plasticity 313 confers multiple fitness benefits to a mimic. Current Biology 25, 949-954.

314 R Development Core Team (2015). R: A language and environment for statistical computing. R 315 Foundation for Statistical Computing, Vienna, Austria. URL http://www.R-project.org/. 
316 Donnelly, W. A. \& Whoriskey Jr., F. G. (1991). Background color acclimation of Brook Trout

317 for crypsis reduces risk of predation by Hooded Mergansers Lophodytes cucullatus. North 318 American Journal of Fisheries Management 11, 206-211.

319 Douglas, M. E. \& Matthews, W. J. (1992). Does morphology predict ecology? Hypothesis 320 testing within a freshwater fish assemblage. Oikos 65, 213-224.

321 Endler, J. A. (1981). An overview of the relationships between mimicry and crypsis. Biological $322 \quad$ Journal of the Limnean Society 16, 25-31.

323 Franssen, N. R., Goodchild, C. G. \& Shepard, D. B. (2015). Morphology predicting ecology:

324 incorporating new methodological and analytical approaches. Environmental Biology of $325 \quad$ Fishes $98(2), 713-724$.

326 Galis, F. (1990). Ecological and morphological aspects of change in food uptake through the 327 ontogeny of Haplochromis piceatus. In: Behavioural mechanisms of food selection.

328 Proceedings of the NATO advanced research workshop on behavioural mechanisms of food

329 selection (Hughes, R. N. ed). pp 281-302, Berlin, Springer.

330 Gibran, F. Z. (2010). Habitat partitioning, habits and convergence among coastal nektonic fish 331 species from the São Sebastião Channel, southeastern Brazil. Neotropical Ichthyology 8, 299332310.

333 Gómez-Laplaza L. M. \& Gerlai, R. (2013). The Role of Body Surface Area in Quantity 334 Discrimination in Angelfish (Pterophyllum scalare). PLoS ONE 8 (12): e83880. 335 doi:10.1371/journal.pone.0083880

336 Gushima, K. \& Murakami, Y. (1976). The reef fish fauna of Kuchierabu, offshore island of 337 southern Japan. Journal of the Faculty of Fisheries and Animal Husbandry 15, 47-56.

338 Hamner, W. M. (1995). Predation, cover, and convergent evolution in epipelagic oceans. Marine 
and Freshwater Behaviour and Physiology 26, 71-89.

340 Jenkins, J. A., H. L., Bart Jr, H. L., Bowker, J. D., Bowser, P. R., MacMillan, J. R., Nickum, J.

341 G., Rose, J. D., Sorensen, P. W., Whitledge, G. W., Rachlin, J. W. \& Warkentine, B. E.

342 (2014). Use of Fishes in Research Committee (joint committee of the American Fisheries

343 Society, the American Institute of Fishery Research Biologists, and the American Society of

344 Ichthyologists and Herpetologists). Guidelines for the Use of Fishes in Research. Bethesda,

345 Maryland, USA: American Fisheries Society.

346 Johnsen, S. (2014). Hide and seek in the open sea: Pelagic camouflage and visual

347 countermeasures. Annual Review of Marine Science 6, 369-392.

348 Kelley, J. L. \& Merilaita, S. (2015). Testing the role of background matching and self-shadow

349 concealment in explaining countershading coloration in wild-caught rainbowfish. Biological

$350 \quad$ Journal of the Linnaean Society DOI: 10.1111/bij.12451

351 Kimura, M., Morii, Y., Kuno, T., Nishida, H., Yoshimura, H., Akishige, Y. \& Senta T. (1998)

352 Floatsam ichthyofauna in the tropical waters of the West Pacific Japan. Bulletin of the Faculty

353 of Fisheries, Nagasaki University 79, 9-20.

354 Klingenberg, C. P. (2011). MorphoJ: an integrated software package for geometric

355 morphometrics. Molecular Ecology Resources 11, 353-357.

356 Kuiter, R. H. \& Debelius, H. (2001). Surgeonfishes, Rabbitfishes, and their Relatives: A

357 comprehensive guide to Acanthuroidei. TMC Publishing: Chorleywood, UK.

358 Leis, J. M., Hay, A. C., Sasal, P., Hicks, A.S. \& Galzin, R. (2013). Pelagic to demersal transition

359 in a coral-reef fish, the orbicular batfish Platax orbicularis. Journal of Fish Biology 83 (3),

$360 \quad 466-479$.

361 Loy, A., Mariani, L., Bertelletti, M. \& Tunesi, L. (1998). Visualizing allometry: Geometric 
morphometrics in the study of shape changes in the early stages of the two-banded sea bream, Diplodus vulgaris (Perciformes, Sparidae). Journal of Morphology 237 (2), 137-146.

364 Moland E., Eagle, J. V. \& Jones G. P. (2005). Ecology and evolution of mimicry in coral reef 365 fishes. Oceanography and Marine Biology - An Annual Review 43, 455-482.

366 Motomura, H., Kuriiwa, K., Katayama, E., Senou, H., Ogihara, G., Meguro, M., Matsunuma, M., 367 Takata, Y., Yoshida, T., Yamashita, M., Kimura, S., Endo, H., Murase, A., Iwatsuki, Y., 368 Sakurai, Y., Harazaki, S., Hidaka, K., Izumi, H., \& Matsuura, K. (2010) Annotated checklist 369 of marine and estuarine shes of Yaku-shima Island, Kagoshima, southern Japan. IN:

370 Motonomura, H. \& Matsuura, K. (eds). Fishes of Yaku-shima Island-A World Heritage 371 island in the Osumi Group, Kagoshima Prefecture, southern Japan. National Museum of $372 \quad$ Nature and Science, Tokyo

373 Nakabo, T. (ed) (2002). Fishes of Japan with pictorial keys to the species, English edition. Tokai $374 \quad$ University Press, Tokyo.

375 Nelson, J. S. (2006). Fishes of the world. 4th edn. Wiley, NJ.

376 Nikolioudakis, N., Koumoundouros, G. \& Somarakis, S. (2014). Synchronization in allometric 377 and morphological changes during metamorphosis: Comparisons among four sparid species. 378 Aquatic Biology 21, 155-165.

379 Okiyama, M. (ed) (2014). An Atlas of Early Stage Fishes in Japan, 2nd edition. Tokai University 380 Press, Tokyo.

381 Oliveira, E. F., Goulart, E., Breda, L., Minte-Vera, C.V., Paiva, L.R.S. \& Vismara, M.R. (2010). 382 Ecomorphological patterns of the fish assemblage in a tropical floodplain: effects of trophic, 383 spatial and phylogenetic structures. Neotropical Ichthyology 8, 659-586.

384 Pasteur, G. (1982). A Classification Review of Mimicry Systems. Annual Review of Ecology and 

Systematics 13, 169-199.

386

Randall, J. E. (2005a). A review of mimicry in marine fishes. Zoological Studies 44 (3), 299-328.

Randall, J. E. (2005b). Reef and shore fishes of the South Pacific: New Caledonia to Tahiti and the Pitcairn Island. University of Hawai'i Press, Honolulu

Randall, J. E. \& Randall, H. A. (1960). Examples of mimicry and protective resemblance in tropical marine fishes. Bulletin of Marine Science 10, 444-480.

Robertson, D. R. (2013). Who resembles whom? Mimetic and coincidental look-alikes among tropical reef fishes. PLoS ONE 8 (1): e54939

Roberston, D. R. (2015) Coincidental resemblances among coral reef fishes from different oceans. Coral reefs 34: 977 DOI 10.1007/s00338-015-1309-8

Sazima, I., Carvalho, L. N., Mendonça, F. P. \& Zuanon, J. (2006). Fallen leaves on the waterbed: diurnal camouflage of three night active fish species in an Amazonian streamlet. Neotropical Ichthyology 4 (1), 119-122.

Scholtz, G. (2010). Deconstructing morphology. Acta Zoologica 91, 44-63.

Skelhorn, J., Rowland, H. M. \& Ruxton, G. D. (2010a). The evolution and ecology of masquerade. Biological Journal of the Linnaean Society 99, 1-8.

Skelhorn, J., Rowland, H. M., Speed, M. P. \& Ruxton, G. D. (2010b). Masquerade: Camouflage without crypsis. Science 327, 51.

Soares, B. E., Ruffeil, T. O. B. \& Montag, L. F. A. (2013). Ecomorphological patterns of the fishes inhabiting the tide pools of the Amazonian Coastal Zone, Brazil. Neotropical Ichthyology 11, 845-858.

Uchida, K. (1951). Notes on a few cases of mimicry in fishes. Science Bulletin of the Faculty of Agriculture of Kyushu University 13, 294-296. 
408 Valentin, A. E., Penin, X., Chanut, J.-P., Sévigny, J.-M. \& Rohlf, F. J. (2008) Arching effect on

409 fish body shape in geometric morphometric studies. Journal of Fish Biology 73, 623-638.

410 Vandendriessche, S., Messiaen, M., O'Flynn, S., Vincx, M. \& Degraer, S. (2007). Hiding and

411 feeding in floating seaweed: Floating seaweed clumps as possible refuges or feeding grounds

412 for fishes. Estuarine, Coastal and Shelf Science 71, 691-703.

413 Vane-Wright, R. I. (1980). On the definition of mimicry. Zoological Journal of the Linnean

$414 \quad$ Society 13, 1-6.

415 Venables, W. N. \& Ripley, B. D. (2002). Modern Applied Statistics with S. $4^{\text {th }}$ edition. Springer.

416 Walker, J.A. (2004). Kinematics and performance of maneuvering control surfaces in teleost

417 fishes. IEEE Journal of Oceanic Engineering 3, 572-584.

418 Willey, A. (1904). Leaf-mimicry. Spolia Zeylan 2, 51-55.

419 Wickler, W. (1968). Mimicry in plants and animals. McGraw Hill, New York.

420 Xiong, G. \& Lauder, G. V. (2014). Center of mass motion in swimming fish: effects of speed

421 and locomotor mode during undulatory propulsion. Zoology 117, 269-281.

422

423 Table legends

424 Table I - List of homologous landmarks and criteria adopted for selecting each landmark used 425 for the mimetic fish.

426

\section{Supporting Information}

428 S1 - Schematic map showing the geographic position of Kuchiearbu jima Island in southern 429 Japan.

430 S2 - Dataset used for the GM, ANCOVA and LDA analyses, with the respective scripts for data 
431 replication using R. Specific information on vouchers references from the Kagoshima

$432 \quad$ University Museum are also included.

433 S3 - Video file containing examples of plant-mimetic interactions by several fish species

434 observed at Kuchierabu jima Island, including Platax orbicularis.

435

436 


\section{Table 1 (on next page)}

List of landmarks

List of homologous landmarks and criteria adopted for selecting each landmark used for the mimetic fish 


\begin{tabular}{|c|c|}
\hline Landmark & Landmark description \\
\hline 1 & Tip of the snout \\
\hline 2 & Nasal cavity \\
\hline 3 & Posterior limit of supra-occipital \\
\hline 4 & Anterior insertion of dorsal fin \\
\hline 5 & Edge of last hard spine \\
\hline 6 & Insertion of soft rays \\
\hline 7 & Maximum height of dorsal fin \\
\hline 8 & Posterior insertion of dorsal fin \\
\hline 9 & Upper limit of caudal fin \\
\hline 10 & Hypural joint \\
\hline 11 & Lower limit of caudal fin \\
\hline 12 & Posterior insertion of anal fin \\
\hline 13 & Maximum height of anal fin \\
\hline 14 & Anterior insertion of anal fin \\
\hline 15 & Insertion of pelvic fin \\
\hline 16 & Lower occipital edge \\
\hline
\end{tabular}

1 


\section{Figure 1}

Mimetic fish and plant models

Morphometric comparisons of plant-mimetic juvenile fish associated with plant debris observed on Kuchierabu-jima Island, southern Japan Examples of mimetic fish and their models (i.e. floating plant debris) occurring in the shallow waters of Honmura Port, Kuchierabu-jima Island, southern Japan. a) Lobotes surinamensis, b) Canthidermis maculata and c) Platax orbicularis are the mimetic fish observed. The models were subdivided using three criteria of: d) round leaves, and e) elongated leaves. The established landmarks and semilandmarks are denoted in (a) for the mimetic fish and in (f) for the models, respectively. White bars indicate $1 \mathrm{~cm}$.

*Note: Auto Gamma Correction was used for the image. This only affects the reviewing manuscript. See original source image if needed for review. 


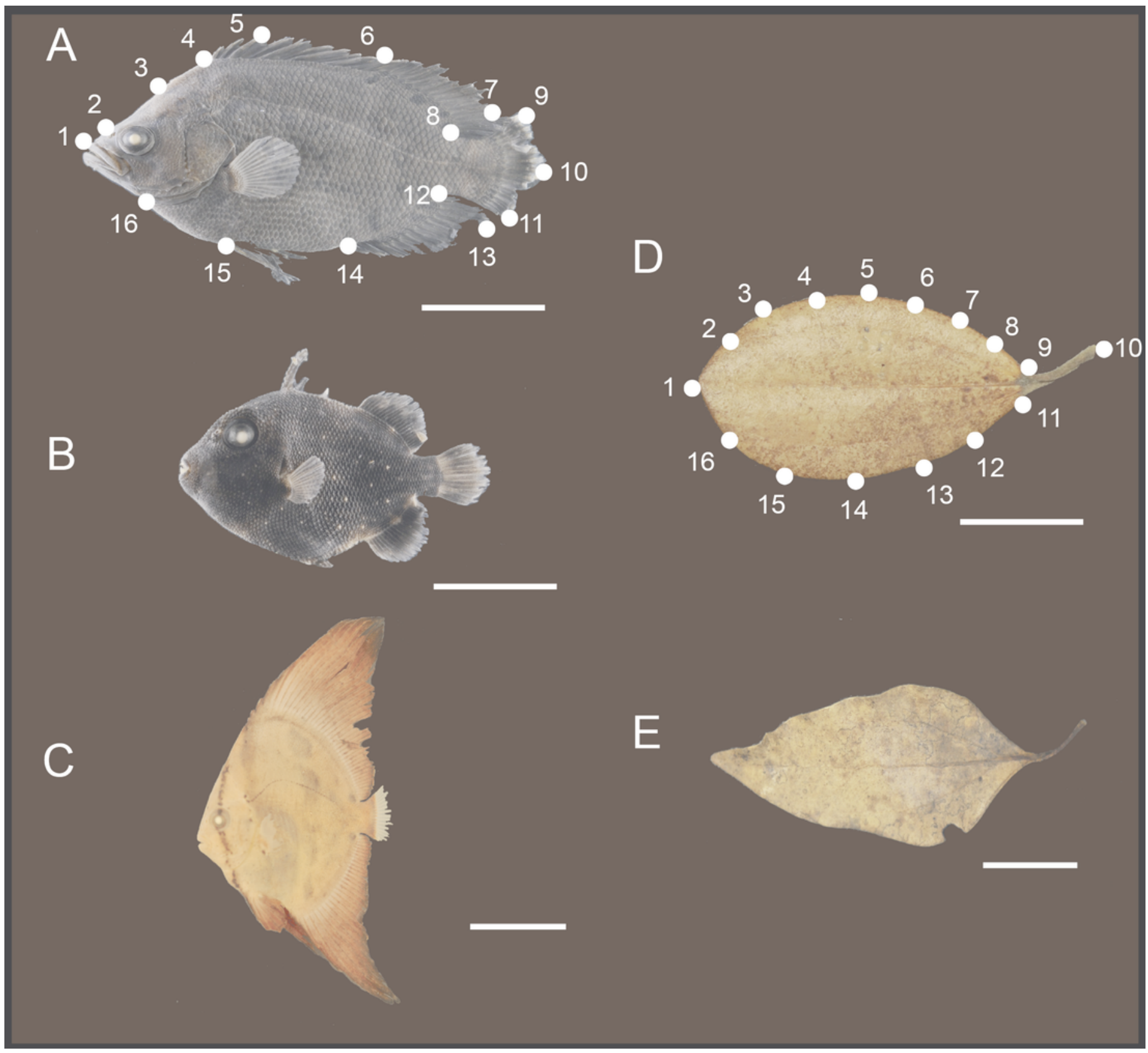




\section{Figure 2 (on next page)}

Morphometric relationships among mimetic fish and plant models

Morphometric comparisons of plant-mimetic juvenile fish associated with plant debris observed on Kuchierabu-jima Island, southern Japan Diversity of shapes observed for the models (i.e. floating plant debris) (a) and fish mimics (b), via a general Procrustes analysis (GPA); and principal components analysis (PCA; C), of all- pooled data indicating a high tendency for shape similarities shared by the mimetic fish and models (i.e. floating plant debris), where green plots represent leaf models (dark green representing rounded leaf models and lighter green representing elongated leaf models). Mimetic fish are represented by Lobotes surinamensis (yellow), Platax orbicularis (red), and Canthidermis maculata (white). 
PeerJ

$A$

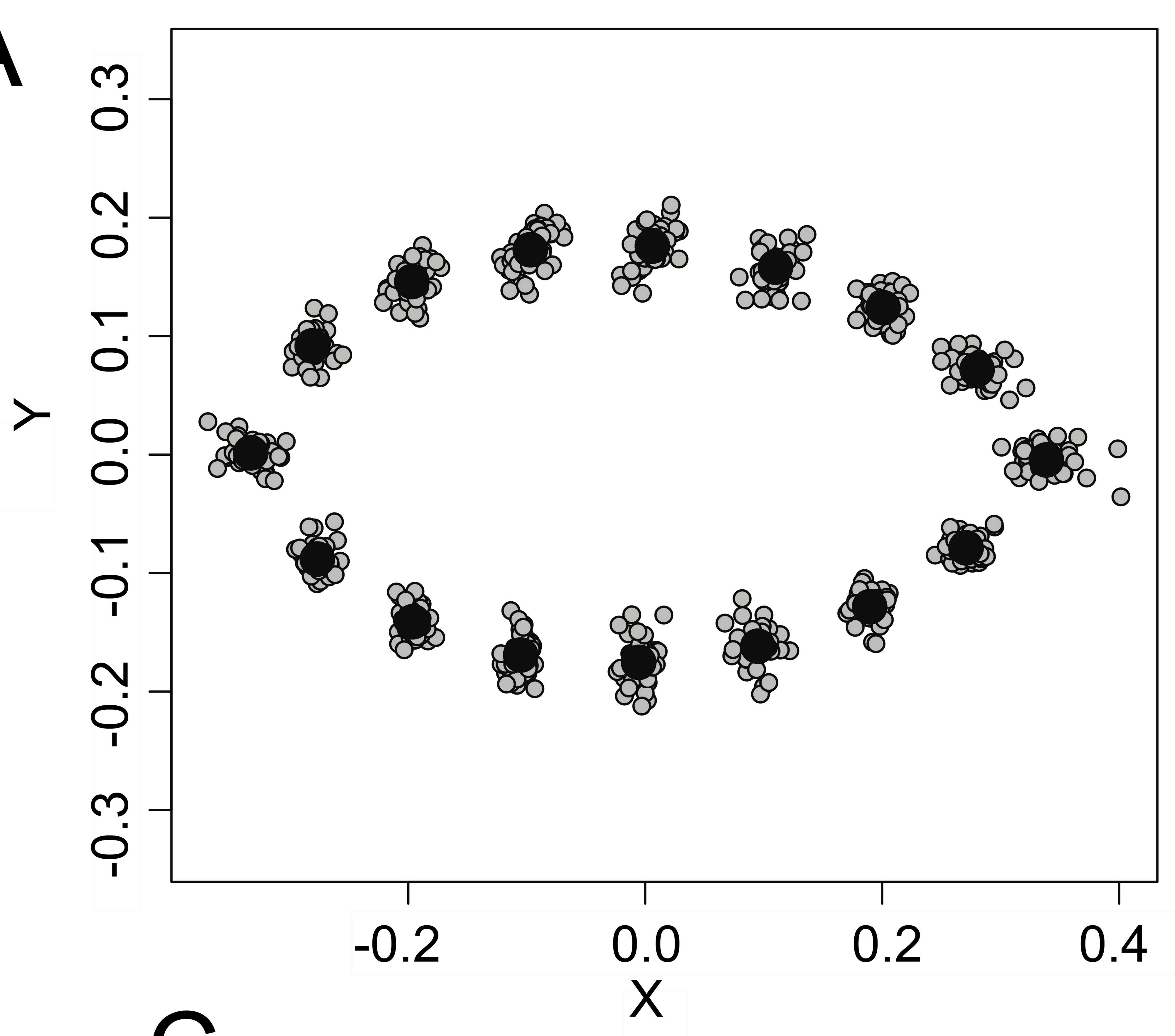

Manuscript to be reviewed

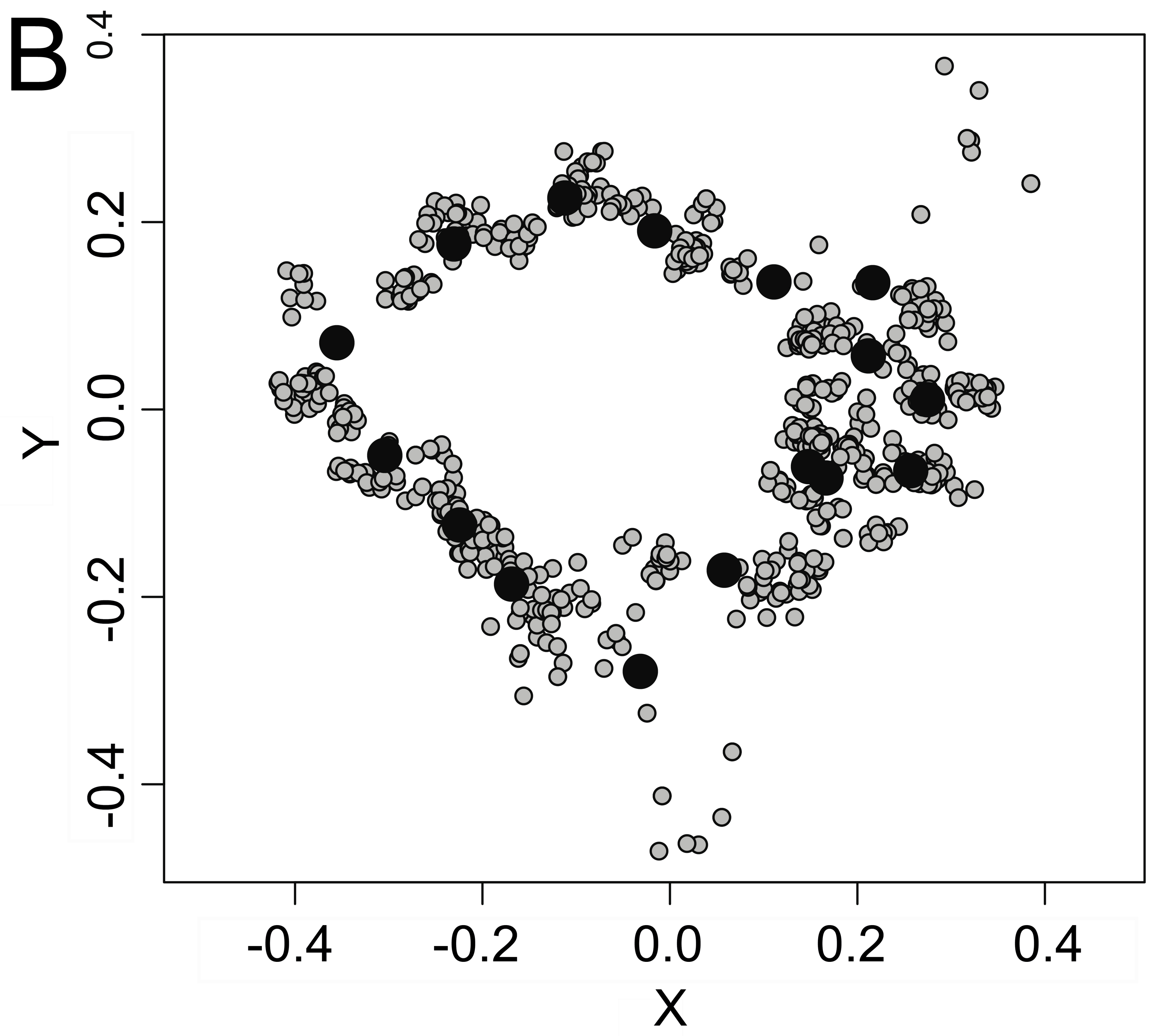

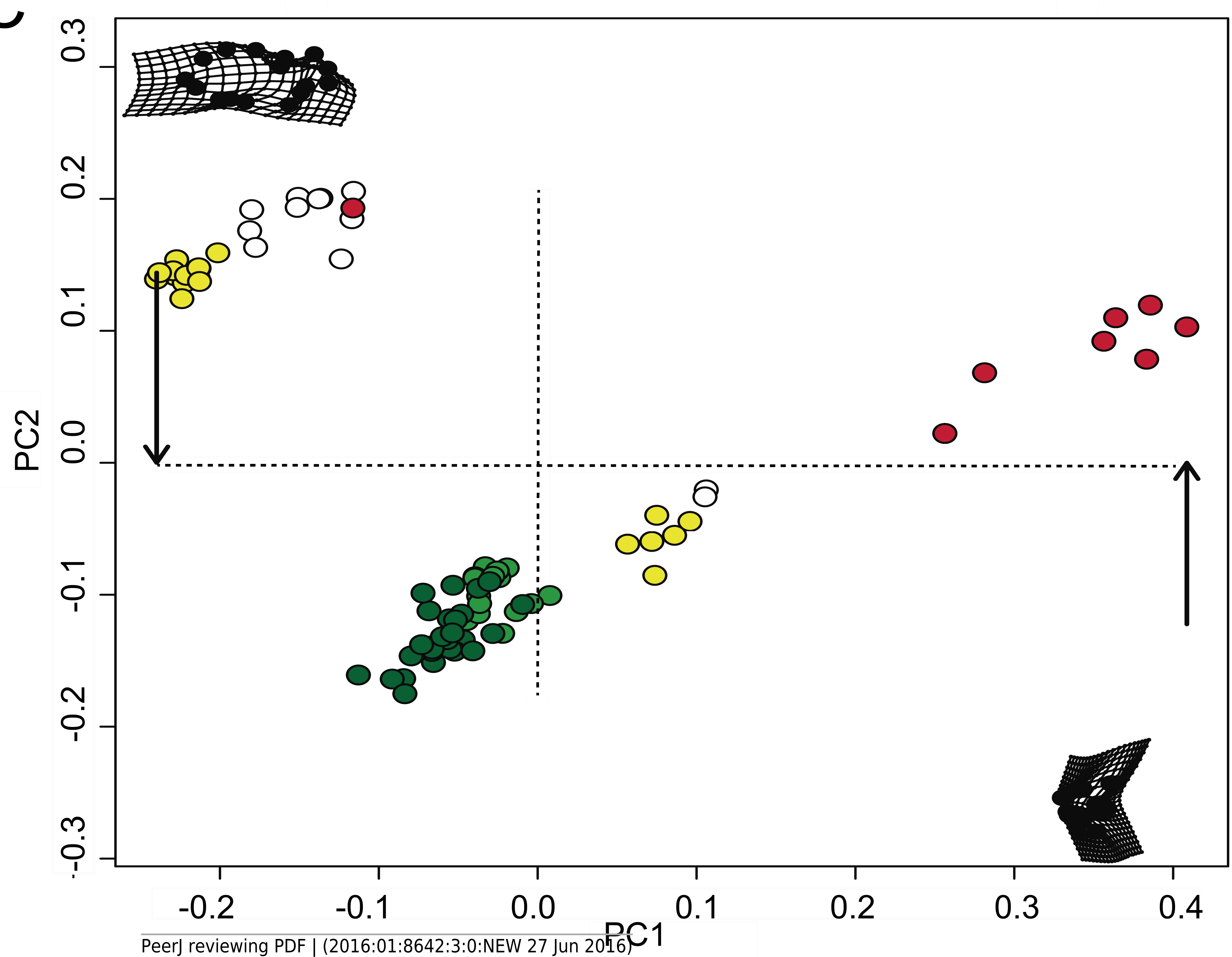


Figure 3

\section{ANCOVA}

Morphometric comparisons of plant-mimetic juvenile fish associated with plant debris observed on Kuchierabu-jima Island, southern Japan Similar relative body area values were observed among the models (i.e. floating plant debris) and mimetic fish, where mimetic fish are represented by Lobotes surinamensis (yellow), Canthidermis maculata (white) and Platax orbicularis (red), and plant models are represented by green plots (dark green representing rounded leaf models and lighter green representing elongated leaf models).

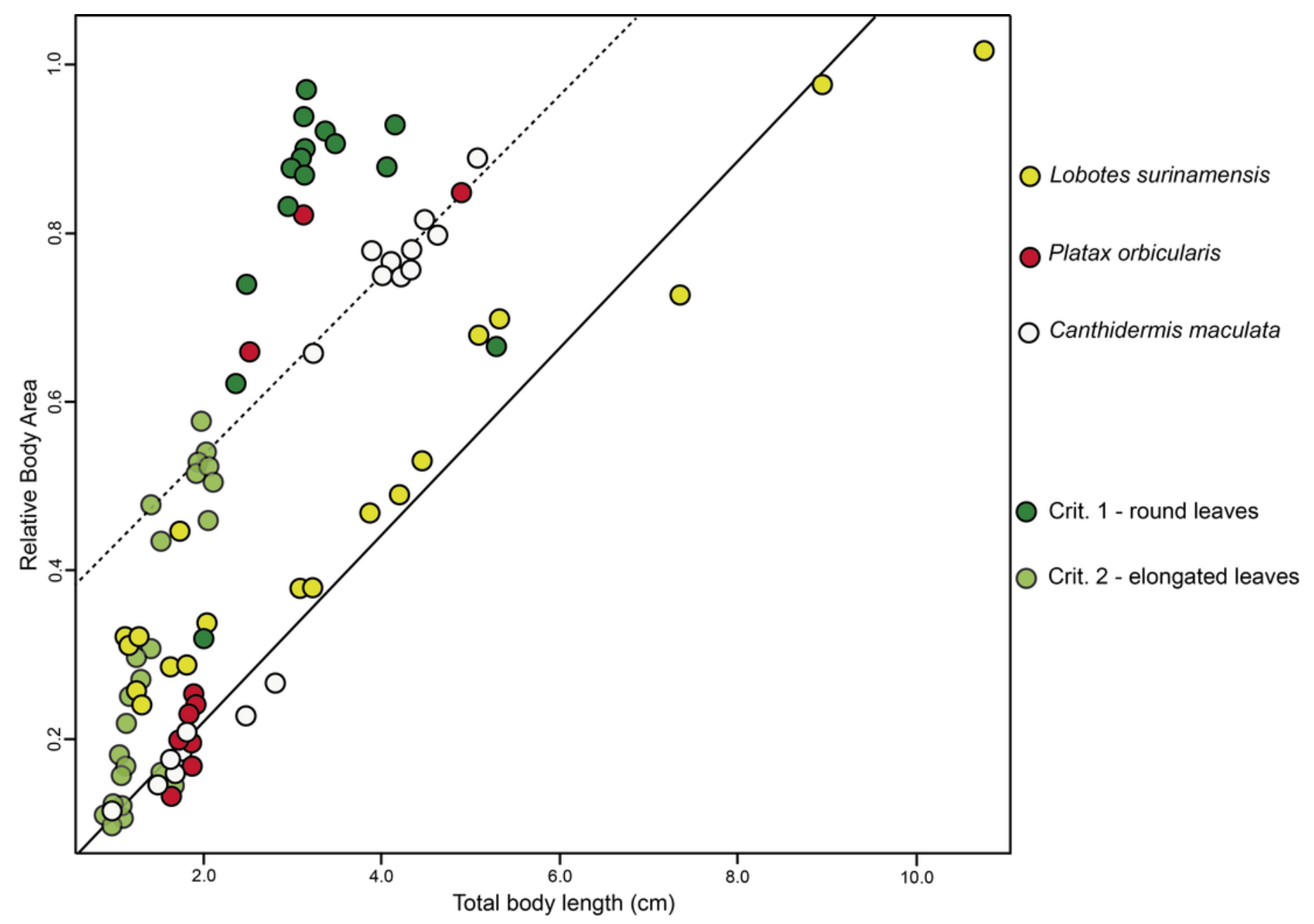

